\title{
Designing an Intelligent In-Home Healthcare System
}

\author{
Maryam Pournasir Roudbaneh ${ }^{1}$, Mehr Ali Hemmatinezhad ${ }^{2}$, Maryam Shamsyan ${ }^{3}$ \\ ${ }^{1}$ Assistant Professor, Department of Management, Lahijan Unit, Islamic Azad University, Lahijan, \\ Iran. Pournasir.m@liau.ac.ir \\ ${ }^{2}$ Professor of Sport Management Department, Gilan University, Rasht, Iran. ma_hemati@yahoo.com \\ ${ }^{3}$ MA Student in Information Technology Management, Rahbord Shomal University, Rasht, Iran. \\ tina_shamsyan@yahoo.com
}

\begin{tabular}{l} 
ARTICLE INFO \\
\hline Keywords: \\
In-Home Care Services \\
Data Warehouse \\
OLAP \\
Topsis
\end{tabular}

\begin{abstract}
Due to the middle-aged population, the need for health services is increasing and more staff is required to visit and serve the homes of the elderly people. For many years, the shortage of specialized nurses and hard service programs has created a lot of pressure on health service centers and sometimes caused complaints of family members or elderly people. In order to have a good quality of these services, having an assessment strategy is required by determining the workload and staff personality of the nursing section. In this research, an in- home care institution was selected. Initially, a survey was conducted on the elderly people and their families. Data was then managed using OLAP technology. One month after the implementation of the system, the survey was re-evaluated and then, using the Topsis method, the nurses' performance was ranked. The results showed that the satisfaction of the elderly people and their families from the in-home care institute has been promoted in all three dimensions of technical-vocational, training and trust, but there is still a degree of dissatisfaction.
\end{abstract}

\section{Introduction}

Due to the middle-aged population, the need for health services is increasing and more staff is required to visit and serve the homes of the elderly people. For many years, the shortage of specialized nurses and hard service programs has created a lot of pressure on health service centers and sometimes caused complaints of family members or elderly people. In order to have a good quality of these services, having an assessment strategy is required by determining the workload and staff personality of the nursing section. The Smart Performance Assessment System is designed to assess the performance of the staff of nursing section in the health industry. IPAS is the function of process of Intent of things for collecting and storing data relating to elderly patients, staff of nursing section and health agencies when providing health services in evaluating the quality of services provided by nurses. Therefore, health agencies can design a follow-up program based on assessment results. By conducting a study at the Health and Care Agency, nurse loyalty increases, while improving the quality of home health. The study examines the various aspects of Internet of things and provides architectures and 
levels of various health care networks that support access to IOT strength and facilitate the transfer of medical data. In addition, this research provides partial research activities on how to keep older people and disable people, private care and health management. For a deeper view to industrial trends and technology empowerment, the study tries to provide a broader view of how recent advances in sensors, tools, Internet applications and other technologies that causes the provision of IOT care tools in more developments. To better understand the security of IOT care, this research considers various security requirements and challenges, and presents a variety of research problems to provide a model that can reduce the problems of in-home care from the elderly people and patients.

\section{Subject literature}

\section{A. The record of in-home care services}

Due to the process of aging population around the world, the need for health services, especially long-term care, has increased significantly, which has a major impact on society and the economy. Costs of government in the health sector are continuously increasing, while the need for health care is also facilitated and workers are also rising. As a result, rising costs and resource scarcity in public and private health organizations make the health care workers in difficulty. In such a situation, the health care process changes from public and private healthcare organizations to society, which increases the need for in-home care services (Valerie Tang, 2016).

\section{Online Analytical Processing Technology (OLAP)}

Online Analytical Processing (OLAP) has been emerged as a "Break Through" technology that can provide the basis of EIS solutions. Using OLAP, senior executives are able to see hundreds of graphical and tabular displays that have visualization of their business process. Since OLAP technology provides user and data scalability, performance, reading / writing ability and computational capabilities, it is in accordance with all data mart requirements. Two other options (personal productivity tools, query and reporting tools) cannot provide the same level of support. Personal productivity tools such as spreadsheets and statistical packets are on PCs, and therefore only a small amount of data is supported by a single user. Query tools and data reports are SQL-driven, and are often used for list-oriented analysis, preliminary analysis, and report generation. These tools do not provide predictable performance or powerful calculations from OLAP. The OLAP technology option I support of collaboration in the business management cycle of report, analyzing, modeling and planning what-if (Khurana, 2015).

\section{How does OLAP technology work?}

How does it work? OLAP technology consists of two main components, the server and the client (the client). Typically, server is a multi-user, LAN-based database that is downloaded from legacy systems or from data warehouse. We do not need a data warehouse to implement OLAP, but if we have historical data, OLAP visualization shows the patterns of business processes that are hidden in the data. The server uses OLAP databases as multidimensional arrays or data cubes (actually cubes from cubes) that can keep hundreds of thousands of rows and columns of text and numbers. The current terms for these database servers are multidimensional databases (MDDs). MDDs are downloaded from a data source (legacy or warehouse) according to a collector model that we define. Fortunately, the definition of the model and the loading of the database can be very easy. For some OLAP products, no coding is needed to make a model or download data. Customer component for multiple OLAP products offers a wide spread interface (Khurana, 2015). 


\section{Research background}

Yaqoobi and Zoghi (2015) in an article titled "The model of health care system in emergency time, based on the Internet of things" stated that today there are many problems for the health status of humans and the improvement of these conditions. Some diseases are easily curable, and some other diseases are unknown to physicians and their treatment has complex conditions. These diseases require access to the same disease information and how to deal with it, in order to minimize the potential risks of incorrect treatment and false diagnosis. Accordingly, the use of the Internet of Things to remove the health problems is an essential issue. The purpose of this article is to provide a model based on Internet of things for helping patients better and faster. A model that in emergency situations with the provision of information and similar actions in the leading field will help doctors to treat patients with higher quality and lower risks. This model, with the availability and sharing of health information as well as the actions taken place and the result of these actions, improves decision-making in emergency situations. Responsiveness and effectiveness in this model is for the processing and provision of data based on the Internet of things.

Qasemi et al. (2016) stated in an article titled "Prioritizing Applications of Technology of Internet of Things in Iran's Healthcare Sector: a Driving for Sustainable Development": Today, there are many problems for people's health and the improvement of these conditions. Some diseases are easily curable, and some other diseases are unknown to physicians and their treatment has complex conditions. These diseases require access to the same disease information and how to deal with it, in order to minimize the potential risks of incorrect treatment and false diagnosis. Accordingly, the use of the Internet of Things to remove the health problems is an essential issue. The purpose of this article is to provide a model based on Internet of things for helping patients better and faster. A model that in emergency situations with the provision of information and similar actions in the leading field will help doctors to treat patients with higher quality and lower risks. This model, with the availability and sharing of health information as well as the actions taken place and the result of these actions, improves decision-making in emergency situations. Responsiveness and effectiveness in this model is for the processing and provision of data based on the Internet of things. Riazol Eslam and colleagues (2015) in an article titled "Internet of Things for Health Cares: A Comprehensive Survey" stated: The Internet of Things (IoT) makes smart things the ultimate structures of construct in physical structures cyber physical. IoT has a variety of functional domains, including health care. The IoT revolution redesigns modern health services, according to the technological, economic and social challenges. This article examines the advances of IoTbased healthcare technology and reviews architecture / operating system, applications and advanced networks in IoT-based healthcare solutions. In addition, this paper examines the security and privacy features defined from the IoT, including security needs, threat models, and attack classification from the perspective of health care.

Al-Ayad and Zhou (2016) in an article entitled "Approval of WSN-Based Patients Based on Intelligent Home Health Care System: An Integrated Model of Facilitators and Obstacles" stated that: patient care is based on the emphasis on coordination and care communication through active participation of patients, their families, doctors and other professionals to improve decision making. Intelligent telecommunication technology and the Internet of things like wireless-sensor-based in-home healthcare systems (WSN-SHHS) facilitate communication and collaboration among these different roles. They described the research problem as: Despite the high potential of such systems for improving quality and experience and reducing the costs of health care, technology has not been widely accepted due to inadequate understanding of user expectations, needs, and preferences. This study refers to the facilitators and barriers associated with accepting WSN-SHHS by identifying important social, technical, cognitive, emotional and background factors. They also continued: We identified 
several new structures in connection with the adoption of WSN-SHHS, including human concerns, privacy concerns, life expectancy and cost concerns. In addition, we confirmed the structures from the general acceptance model.

\section{Research method}

Considering that the purpose of this research is to provide an IPAS system, it can be said that this research is applied objectively and essentially descriptive-survey. In this research, in order to design an IPAS system, after consulting with the supervisor, it was decided to choose an inhome care institution located in Rasht city. In order to collect information, library and field methods were used.

1) Library studies: To formulate the basics, definitions and theoretical concepts, library resources were used, the most important and useful source has been articles, theses, conferences and books related to the subject of research, databases and information resources, and libraries of the universities of the country.

2) Field research: To collect information for providing an IPAS system, data of an in-home care institution was used that provides in-home nursing counseling and services in Rasht. Also, for collecting data to assess the satisfaction of the elderly people from the Institute and assessing the performance of the nurses of the institute, the views of the elderly people and their families were used which obtained by telephone. Because it does not have the tendency to name the institution, it is called A.

\section{Findings}

\section{Introducing the institute studied}

In-home care institution A (because management doesn't have tendency to name the institution, we call it A) was established in 2009 and is located in Rasht. It provides in-home care services in long-term, including personal care, medical care and domestic help, for elderly people and others with Alzheimer's disease or other chronic illnesses, as well as disabled people. Apart from long-term in-home care services, it provides short-term special services to customers according to their needs. For example, there are services, including companion of patients in the hospital, for those elderly or patients who do not have relatives for this purpose, or the provision of supplies for them, including home purchase and home cleaning. This in-home care agency has 20 nurses. The goal of this institution is to create a happy and enjoyable life for the elderly people by providing appropriate in-home care services through professional knowledge of nursing care staff. In this institution, after receiving an order for in-home care services from elderly people or their families, managers of in-home care institute A investigate a patient's history records on a computer to determine which services are required. Based on existing records, they allocate appropriate nurse to serve that particular elderly person. At the same time, they confirm the date and time of booking by phone. Finally, the nurses are looking for a program scheduled by the managers of the institution to go to the elderly home.

\section{Problems at in-home care agency A}

In-home care agency A had received negative feedback and complaints from clients (elderly people and their families) due to the poor quality of services provided by nurses. For example, the complaints were that attitude of nursing staff is weak and they have specific mistakes, such as mistake in the patient's history in in-home care services, late in reaching to the elderly people, and so on. By conducting a study at the in-home care agency A (Interview with the managers of institute), two major problems that reduce customer satisfaction are as follows: A: weak management of data: 
In the in-home care agency, the relevant data is stored in various files. Finding the data was time-consuming for managers of in-home care agency. On the other hand, due to the incorrect updating of the relevant data, some files were lost and, therefore, increased nursing staffing problems to monitor the health status of the elderly people.

B. Lack of a systematic approach in assessing the performance of nursing staff:

Every year, in-home care institute examines the individual performance of nursing staff by assessing performance in order to understand the difficulties in providing in-home care services. But, while complaints from elderly people are high, there is no justification for assessing the performance of nurses. Therefore, it was decided if, after the establishment of the IPAS system, the level of satisfaction of the elderly people from the institution increases, a model for assessing nurses should be considered to be encouraged by offering rewards according to their performance.

It should also be noted that this institute was also faced with a missing order due to the lack of a correct plan for managing orders.

\section{Initial Survey (before implementing the IPAS system)}

According to the dimensions, the result of the survey is as shown in Table 1. The survey is conducted from 50 elderly people or their families.

Table 1: The result of the survey before running the IPAS system

\begin{tabular}{|l|l|l|l|l|l|}
\hline $\begin{array}{l}\text { Dimensions of } \\
\text { satisfaction of patient }\end{array}$ & Very high & High & Medium & Little & $\begin{array}{l}\text { Very } \\
\text { little }\end{array}$ \\
\hline Technical-vocational & 5 & 5 & - & 25 & 15 \\
\hline Education & - & 20 & - & 30 & - \\
\hline Trust & 3 & 7 & - & 30 & 10 \\
\hline
\end{tabular}

In the technical and vocational dimension, 5 people had very high satisfaction, 5 people had high satisfaction, 25 people had low satisfaction and 15 people had very little satisfaction. In the education dimension, 20 people had high satisfaction and 30 people had little satisfaction. In the trust dimension, 3 people had very high satisfaction, 7 people had high satisfaction, 30 people had low satisfaction and 10 people had very little satisfaction.

\section{IPAS implementation}

In order to help managers of in-home care institution A, it was decided to use IPAS to evaluate service performance of nurses in developing appropriate follow-up plan to improve the quality of in-home care services. At IPAS, first of all, three types of data were collected including inhome care institution, the elderly people and nurses from April 2017 to December 2017 in the form of Microsoft Access 2016 software. An example of the data collected is listed in Table 2.

Table 2: Examples of data to build a data warehouse

\begin{tabular}{|l|l|}
\hline Types of data & Examples \\
\hline $\begin{array}{l}\text { in-home } \\
\text { institution }\end{array}$ & $\begin{array}{l}\text { Number of nursing staff, number of resources, number } \\
\text { of orders received }\end{array}$ \\
\hline Elderly people & Name, type of disease, level of service satisfaction \\
\hline Nurses & $\begin{array}{l}\text { Level of education, number of hours of work, years of } \\
\text { experience }\end{array}$ \\
\hline
\end{tabular}


In order to standardize data in different formats, preprocessing of data (ETL) is required before data transfer to the data warehouse. Figure 2 shows the structure of the data warehouse. After creating the data warehouse, the data was imported into the Microsoft SQL Server 2014 software to create an OLAP cube. The multidimensional view of the OLAP data cube allows managers of in-home care institute to effectively access the data in the in-home care services and analyze them. By developing a hierarchical structure of dimensions in OLAP, managers of in-home care institute A can use operational functions such as investigating based on a dimension or multi-dimension and rotation of dimensions, and to view details of the information system. Managers of in-home care institute A can extract resource information by digging (downward movement) the dimensions of resources in an OLAP data cube.

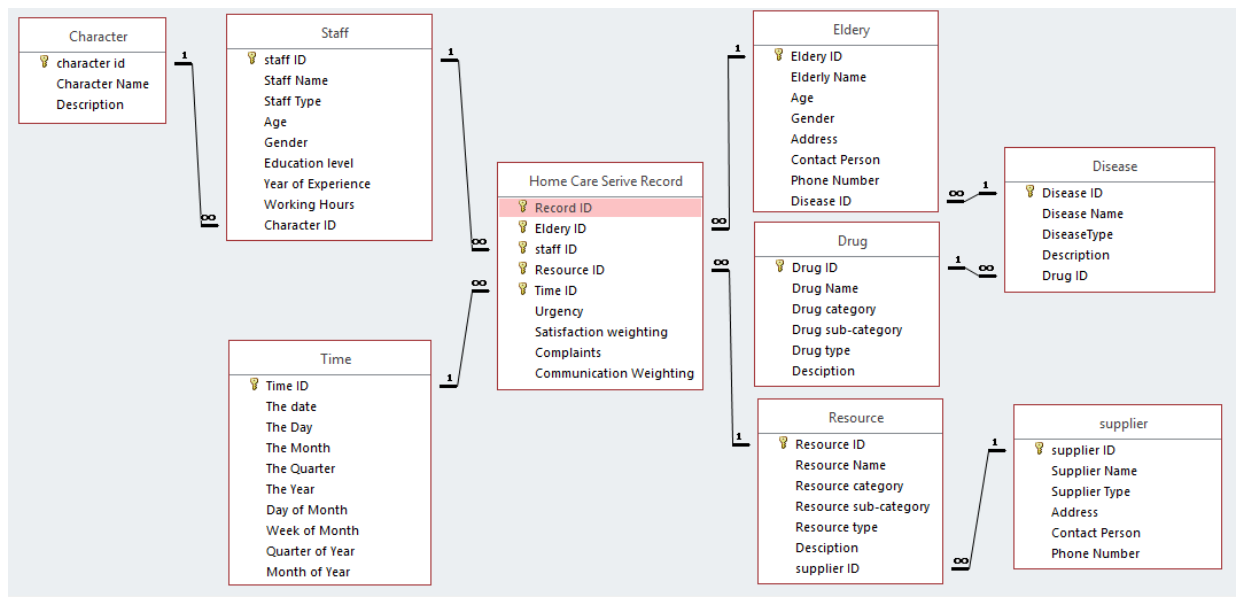

Figure 2: Data warehouse structure

\section{$\begin{array}{llll}\text { Re-survey } & \text { (after } & \text { implementing }\end{array}$}

One month after the implementation of this system, the survey was done as previous method, which the summary of results is as Table 3 .

Table 3: Result of survey after implementing IPAS system

\begin{tabular}{|l|l|l|l|l|l|}
\hline $\begin{array}{l}\text { Dimensions of } \\
\text { satisfaction of patient }\end{array}$ & Very high & High & Medium & Little & $\begin{array}{l}\text { Very } \\
\text { little }\end{array}$ \\
\hline Technical-vocational & 10 & 25 & - & 10 & 5 \\
\hline Education & 15 & 30 & - & 5 & - \\
\hline Trust & 15 & 20 & - & 15 & - \\
\hline
\end{tabular}

As expected, the satisfaction of the recipient's services from the institution has increased in all its dimensions. However, there is still a considerable amount of dissatisfaction. In the technical and vocational dimension, 10 people had very high satisfaction, 25 people had high satisfaction, 10 people had low satisfaction and 5 people had very little satisfaction. In the education dimension, 15 people had high satisfaction, 30 people had high satisfaction and 30 people had little satisfaction. In the trust dimension, 15 people had very high satisfaction, 20 people had high satisfaction, and 15 people had little satisfaction.

Analysis of the results of elderly satisfaction assessment from in-home care institute A before and after the establishment of the IPAS system

In this step, we will review the data from the survey before running the IPAS system and afterwards. 
First, descriptive findings of the research have been presented. This section consists of describing the underlying variables and describing the main research variables. Subsequently, the inferential findings of the research will be presented. In this section, we will also examine and test the assumptions of the present research.

\section{Describing the main variables of research}

Table 4 shows the mean, standard deviation and variance of the research variables.

Table 4: Description of research variable

\begin{tabular}{|l|l|l|l|}
\hline Variable SD & Mean & Variance \\
\hline $\begin{array}{l}\text { Technical and vocational before } \\
\text { deployment of the IPAS system }\end{array}$ & 2.20 & 1.26 & 1.59 \\
\hline $\begin{array}{l}\text { Training before deployment of the } \\
\text { IPAS system }\end{array}$ & 2.80 & 0.98 & 0.98 \\
\hline $\begin{array}{l}\text { Trust before deploying the IPAS } \\
\text { system }\end{array}$ & 2.26 & 1.12 & 1.25 \\
\hline $\begin{array}{l}\text { Technical and vocational after IPAS } \\
\text { system deployment }\end{array}$ & 3.5 & 1.29 & 1.68 \\
\hline $\begin{array}{l}\text { Training after IPAS system } \\
\text { deployment }\end{array}$ & 4.10 & 0.83 & 0.70 \\
\hline Trust after IPAS system deployment & 3.70 & 1.19 & 1.43 \\
\hline
\end{tabular}

\section{Inferential Findings \\ Normality test}

Many of the attributes or features in the statistical population are generally distributed. i.e, most of the values are around the average category, and few are at the top of the degree. If the features of the statistical population are to be carefully estimated from the features of the sample group, the sample group should be chosen in such a way that follows the same normal distribution that is in population (Sekaran, 2012). In this research, the normality of data was investigated by Kolmogrov-Smirnov test in SPSS software and sig values less than 0.05 were obtained. Therefore, the distribution of the data of the research variables is not normal, and nonparametric tests should be used for analysis.

Table 5: Normality test

\begin{tabular}{|l|l|l|}
\hline Variable & Z static & Sig \\
\hline $\begin{array}{l}\text { Technical and vocational before deployment of } \\
\text { the IPAS system }\end{array}$ & 0.363 & 0.000 \\
\hline Training before deployment of the IPAS system & 0.391 & 0.000 \\
\hline Trust before deploying the IPAS system & 0.392 & 0.000 \\
\hline $\begin{array}{l}\text { Technical and vocational after IPAS system } \\
\text { deployment }\end{array}$ & 0.350 & 0.000 \\
\hline Training after IPAS system deployment & 0.353 & 0.000 \\
\hline Trust after IPAS system deployment & 0.299 & 0.000 \\
\hline
\end{tabular}

\section{Investigating hypotheses}

\section{Investigating the first hypothesis}

In the first hypothesis, it was predicted that after the implementation of the system, the satisfaction of the service users in the technical and vocational dimension would be significantly improved. Wilcoxon signed-rank test was used to examine this issue. Since the 
significance level is less than 0.05 , the first hypothesis is confirmed at a confidence level of $99 \%$.

Table 6: Investigating the first hypothesis

\begin{tabular}{|l|l|l|l|}
\hline Position of technical and vocational dimension & Numbers & $\begin{array}{l}\text { Wilcoxon } \\
\text { statistic }\end{array}$ & Sig \\
\hline $\begin{array}{l}\text { Technical and vocational after deployment of } \\
\text { larger system before deployment of it }\end{array}$ & 40 cases & -5.719 & 0.000 \\
\cline { 1 - 2 } $\begin{array}{l}\text { Technical and vocational after deployment of } \\
\text { smaller system before deployment of it }\end{array}$ & 0 case & & \\
\cline { 1 - 2 } Technical and vocational before and after & 10 cases \\
deployment of non-change system & & \\
\hline
\end{tabular}

\section{Investigating the second hypothesis}

In the second hypothesis, it was predicted that after the implementation of the system, the satisfaction of the service users in the education dimension would be significantly improved. Wilcoxon signed-rank test was used to examine this issue. Since the significance level is less than 0.05 , the second hypothesis is confirmed at a confidence level of $99 \%$.

Table 7: Investigating the second hypothesis

\begin{tabular}{|l|l|l|l|}
\hline Position of education dimension & Numbers & $\begin{array}{l}\text { Wilcoxon } \\
\text { statistic }\end{array}$ & Sig \\
\hline $\begin{array}{l}\text { Education after deployment of larger system } \\
\text { before deployment of it }\end{array}$ & 40 cases & -5.719 & 0.000 \\
\cline { 1 - 2 } $\begin{array}{l}\text { Education after deployment of smaller system } \\
\text { before deployment of it }\end{array}$ & 0 case & & \\
\cline { 1 - 2 } $\begin{array}{l}\text { Education before and after deployment of non- } \\
\text { change system }\end{array}$ & 10 cases & & \\
\hline
\end{tabular}

\section{Investigating the third hypothesis}

In the third hypothesis, it was predicted that after the implementation of the system, the satisfaction of the service users in the trust dimension would be significantly improved. Wilcoxon signed-rank test was used to examine this issue. Since the significance level is less than 0.05 , the third hypothesis is confirmed at a confidence level of $99 \%$.

Table 8: Investigating the third hypothesis

\begin{tabular}{|l|l|l|l|}
\hline Position of trust dimension & Numbers & $\begin{array}{l}\text { Wilcoxon } \\
\text { statistic }\end{array}$ & Sig \\
\cline { 1 - 2 } $\begin{array}{l}\text { Trust after deployment of larger system before } \\
\text { deployment of it }\end{array}$ & 42 cases & -5.719 & 0.000 \\
\cline { 1 - 2 } $\begin{array}{l}\text { Trust after deployment of smaller system before } \\
\text { deployment of it }\end{array}$ & 0 case & & \\
\cline { 1 - 2 } $\begin{array}{l}\text { Trust before and after deployment of non-change } \\
\text { system }\end{array}$ & 8 cases & & \\
\hline
\end{tabular}

After the in-home care institution, A found that satisfaction of elderly people and their families is increased, because it considers this as a result of improving quality of work of nurses, it decided to evaluate nurses for rating them to encourage them.

To design the TOPSIS-based performance evaluation module, nurses' performance evaluation 
indicators were determined according to the views of the managers of the institute, considering the priorities of the elderly and their families. Then, 50 elderly people and their families were randomly selected and interviewed with them by telephone. The other steps of the second module are described in the form of topsis.

\section{TOPSIS-based performance evaluation}

Step 1: Create a decision matrix

The decision matrix consists of 20 options that includes nurses and 6 indicators include: respect for the elderly people, observing privacy of the elderly people, regular provision of pharmaceutical services, providing health and care, timely attendance at the elderly people's home and the status of clothing and nurse's personal cleaning. (Table 9).

Table 9: Decision matrix

\begin{tabular}{|c|c|c|c|c|c|c|}
\hline Matrix & $\begin{array}{l}\text { Respect for } \\
\text { elderly } \\
\text { people }\end{array}$ & $\begin{array}{l}\text { Observing } \\
\text { the privacy } \\
\text { of the } \\
\text { elderly } \\
\text { people }\end{array}$ & $\begin{array}{l}\text { Regular } \\
\text { provision } \\
\text { of } \\
\text { pharmaceut } \\
\text { ical } \\
\text { services }\end{array}$ & $\begin{array}{l}\text { Providing } \\
\text { health and } \\
\text { care }\end{array}$ & $\begin{array}{l}\text { Timely } \\
\text { attendance } \\
\text { at the } \\
\text { elderly } \\
\text { people's } \\
\text { home }\end{array}$ & $\begin{array}{l}\text { Status of } \\
\text { clothing } \\
\text { and Nurse's } \\
\text { personal } \\
\text { cleaning }\end{array}$ \\
\hline 1 & 5 & 5 & 7 & 7 & 7 & 5 \\
\hline 2 & 6 & 6 & 5 & 7 & 7 & 3 \\
\hline 3 & 6 & 5 & 5 & 7 & 8 & 5 \\
\hline 4 & 7 & 7 & 6 & 9 & 9 & 7 \\
\hline 5 & 4 & 4 & 6 & 7 & 5 & 5 \\
\hline 6 & 8 & 8 & 9 & 7 & 9 & 9 \\
\hline 7 & 7 & 7 & 5 & 5 & 7 & 5 \\
\hline 8 & 6 & 5 & 5 & 4 & 5 & 5 \\
\hline 9 & 5 & 5 & 5 & 5 & 3 & 7 \\
\hline 10 & 5 & 5 & 6 & 8 & 5 & 5 \\
\hline 11 & 7 & 7 & 5 & 5 & 5 & 7 \\
\hline 12 & 3 & 3 & 5 & 7 & 5 & 5 \\
\hline 13 & 3 & 5 & 5 & 5 & 3 & 5 \\
\hline 14 & 9 & 9 & 7 & 5 & 7 & 7 \\
\hline 15 & 3 & 3 & 5 & 7 & 5 & 4 \\
\hline 16 & 4 & 4 & 5 & 5 & 1 & 7 \\
\hline 17 & 5 & 3 & 7 & 7 & 5 & 5 \\
\hline 18 & 5 & 5 & 5 & 5 & 7 & 5 \\
\hline 19 & 3 & 3 & 5 & 5 & 5 & 5 \\
\hline 20 & 5 & 7 & 5 & 6 & 6 & 6 \\
\hline Criterion & Positive & Positive & Positive & Positive & Positive & Positive \\
\hline $\begin{array}{l}\text { Weight of } \\
\text { criterion }\end{array}$ & 0.2148 & 0.2215 & 0.0694 & 0.0918 & 0.286 & 0.1166 \\
\hline
\end{tabular}


Step 2: Normalizing or non-scaling the matrix with Euclidean distance (Second degree)

Table 10: Non-scale matrix

\begin{tabular}{|c|c|c|c|c|c|c|}
\hline $\begin{array}{l}\text { Non-scale } \\
\text { Matrix }\end{array}$ & $\begin{array}{l}\text { Respect for } \\
\text { elderly } \\
\text { people }\end{array}$ & $\begin{array}{l}\text { Observing } \\
\text { the privacy } \\
\text { of the } \\
\text { elderly } \\
\text { people }\end{array}$ & $\begin{array}{l}\text { Regular } \\
\text { provision } \\
\text { of } \\
\text { pharmaceut } \\
\text { ical } \\
\text { services }\end{array}$ & $\begin{array}{l}\text { Providing } \\
\text { health and } \\
\text { care }\end{array}$ & $\begin{array}{l}\text { Timely } \\
\text { attendance } \\
\text { at the } \\
\text { elderly } \\
\text { people's } \\
\text { home }\end{array}$ & $\begin{array}{l}\text { Status of } \\
\text { clothing } \\
\text { and Nurse's } \\
\text { personal } \\
\text { cleaning }\end{array}$ \\
\hline 1 & 0.2011 & 0.2008 & 0.2723 & 0.2492 & 0.2598 & 0.1943 \\
\hline 2 & 0.2414 & 0.241 & 0.1945 & 0.2492 & 0.2598 & 0.1166 \\
\hline 3 & 0.2414 & 0.2008 & 0.1945 & 0.2492 & 0.2969 & 0.1943 \\
\hline 4 & 0.2816 & 0.2811 & 0.2334 & 0.3204 & 0.334 & 0.2721 \\
\hline 5 & 0.1609 & 0.1606 & 0.2334 & 0.2492 & 0.1856 & 0.1943 \\
\hline 6 & 0.3218 & 0.3213 & 0.3501 & 0.2492 & 0.334 & 0.3498 \\
\hline 7 & 0.2816 & 0.2811 & 0.1945 & 0.178 & 0.2598 & 0.1943 \\
\hline 8 & 0.2414 & 0.2008 & 0.1945 & 0.1424 & 0.1856 & 0.1943 \\
\hline 9 & 0.2011 & 0.2008 & 0.1945 & 0.178 & 0.1113 & 0.2721 \\
\hline 10 & 0.2011 & 0.2008 & 0.2334 & 0.2848 & 0.1856 & 0.1943 \\
\hline 11 & 0.2816 & 0.2811 & 0.1945 & 0.178 & 0.1856 & 0.2721 \\
\hline 12 & 0.1207 & 0.1205 & 0.1945 & 0.2492 & 0.1856 & 0.1943 \\
\hline 13 & 0.1207 & 0.2008 & 0.1945 & 0.178 & 0.1113 & 0.1943 \\
\hline 14 & 0.362 & 0.3614 & 0.2723 & 0.178 & 0.2598 & 0.2721 \\
\hline 15 & 0.1207 & 0.1205 & 0.1945 & 0.2492 & 0.1856 & 0.1555 \\
\hline 16 & 0.1609 & 0.1606 & 0.1945 & 0.178 & 0.0371 & 0.2721 \\
\hline 17 & 0.2011 & 0.1205 & 0.2723 & 0.2492 & 0.1856 & 0.1943 \\
\hline 18 & 0.2011 & 0.2008 & 0.1945 & 0.178 & 0.2598 & 0.1943 \\
\hline 19 & 0.1207 & 0.1205 & 0.1945 & 0.178 & 0.1856 & 0.1943 \\
\hline 20 & 0.2011 & 0.2811 & 0.1945 & 0.2136 & 0.2227 & 0.2332 \\
\hline
\end{tabular}

Step 3: Weighing the normalized matrix with Shannon entropy

Table 11: Weight non-scale matrix

\begin{tabular}{|c|c|c|c|c|c|c|}
\hline $\begin{array}{l}\text { Weight } \\
\text { Matrix }\end{array}$ & $\begin{array}{l}\text { Respect for } \\
\text { elderly } \\
\text { people }\end{array}$ & $\begin{array}{l}\text { Observing } \\
\text { the privacy } \\
\text { of the } \\
\text { elderly } \\
\text { people }\end{array}$ & $\begin{array}{l}\text { Regular } \\
\text { provision } \\
\text { of } \\
\text { pharmaceut } \\
\text { ical } \\
\text { services }\end{array}$ & $\begin{array}{l}\text { Providing } \\
\text { health and } \\
\text { care }\end{array}$ & $\begin{array}{l}\text { Timely } \\
\text { attendance } \\
\text { at the } \\
\text { elderly } \\
\text { people's } \\
\text { home }\end{array}$ & $\begin{array}{l}\text { Status of } \\
\text { clothing } \\
\text { and Nurse's } \\
\text { personal } \\
\text { cleaning }\end{array}$ \\
\hline 1 & 0.0432 & 0.0445 & 0.0189 & 0.0229 & 0.0743 & 0.0227 \\
\hline 2 & 0.0518 & 0.0534 & 0.0135 & 0.0229 & 0.0743 & 0.0136 \\
\hline 3 & 0.0518 & 0.0445 & 0.0135 & 0.0229 & 0.0849 & 0.0227 \\
\hline 4 & 0.0605 & 0.0623 & 0.0162 & 0.0294 & 0.0955 & 0.0317 \\
\hline 5 & 0.0346 & 0.0356 & 0.0162 & 0.0229 & 0.0531 & 0.0227 \\
\hline 6 & 0.0691 & 0.0712 & 0.0243 & 0.0229 & 0.0955 & 0.0408 \\
\hline 7 & 0.0605 & 0.0623 & 0.0135 & 0.0163 & 0.0743 & 0.0227 \\
\hline 8 & 0.0518 & 0.0445 & 0.0135 & 0.0131 & 0.0531 & 0.0227 \\
\hline 9 & 0.0432 & 0.0445 & 0.0135 & 0.0163 & 0.0318 & 0.0317 \\
\hline 10 & 0.0432 & 0.0445 & 0.0162 & 0.0261 & 0.0531 & 0.0227 \\
\hline
\end{tabular}




\begin{tabular}{|l|l|l|l|l|l|l|}
\hline $\mathbf{1 1}$ & 0.0605 & 0.0623 & 0.0135 & 0.0163 & 0.0531 & 0.0317 \\
\hline $\mathbf{1 2}$ & 0.0259 & 0.0267 & 0.0135 & 0.0229 & 0.0531 & 0.0227 \\
\hline $\mathbf{1 3}$ & 0.0259 & 0.0445 & 0.0135 & 0.0163 & 0.0318 & 0.0227 \\
\hline $\mathbf{1 4}$ & 0.0778 & 0.0801 & 0.0189 & 0.0163 & 0.0743 & 0.0317 \\
\hline $\mathbf{1 5}$ & 0.0259 & 0.0267 & 0.0135 & 0.0229 & 0.0531 & 0.0181 \\
\hline $\mathbf{1 6}$ & 0.0346 & 0.0356 & 0.0135 & 0.0163 & 0.0106 & 0.0317 \\
\hline $\mathbf{1 7}$ & 0.0432 & 0.0267 & 0.0189 & 0.0229 & 0.0531 & 0.0227 \\
\hline $\mathbf{1 8}$ & 0.0432 & 0.0445 & 0.0135 & 0.0163 & 0.0743 & 0.0227 \\
\hline $\mathbf{1 9}$ & 0.0259 & 0.0267 & 0.0135 & 0.0163 & 0.0531 & 0.0227 \\
\hline $\mathbf{2 0}$ & 0.0432 & 0.0623 & 0.0135 & 0.0196 & 0.0637 & 0.0272 \\
\hline
\end{tabular}

Step 4: Determining positive and negative ideal solution

Table 12: positive and negative ideal solution

\begin{tabular}{|c|c|c|c|c|c|c|}
\hline $\begin{array}{l}\text { Optimal } \\
\text { solution }\end{array}$ & $\begin{array}{l}\text { Respect for } \\
\text { elderly } \\
\text { people }\end{array}$ & $\begin{array}{l}\text { Observing } \\
\text { the privacy } \\
\text { of the } \\
\text { elderly } \\
\text { people }\end{array}$ & $\begin{array}{l}\text { Regular } \\
\text { provision } \\
\text { of } \\
\text { pharmaceut } \\
\text { ical } \\
\text { services }\end{array}$ & $\begin{array}{l}\text { Providing } \\
\text { health and } \\
\text { care }\end{array}$ & $\begin{array}{l}\text { Timely } \\
\text { attendance } \\
\text { at the } \\
\text { elderly } \\
\text { people's } \\
\text { home }\end{array}$ & $\begin{array}{l}\text { Status of } \\
\text { clothing } \\
\text { and Nurse's } \\
\text { personal } \\
\text { cleaning }\end{array}$ \\
\hline+ & 0.0778 & 0.0801 & 0.0243 & 0.0294 & 0.0955 & 0.0408 \\
\hline- & 0.0259 & 0.0267 & 0.0135 & 0.0131 & 0.0106 & 0.0136 \\
\hline
\end{tabular}

The two virtual options are actually the worst and best solution.

Step 5: Determining size of distance from positive and negative ideal solution

Table 13: size of distance from positive and negative ideal solution

\begin{tabular}{|l|l|l|}
\hline Size of distance & + & - \\
\hline $\mathbf{1}$ & 0.0575 & 0.0698 \\
\hline $\mathbf{2}$ & 0.0523 & 0.0744 \\
\hline $\mathbf{3}$ & 0.0504 & 0.0818 \\
\hline $\mathbf{4}$ & 0.0276 & 0.1014 \\
\hline $\mathbf{5}$ & 0.078 & 0.0463 \\
\hline $\mathbf{6}$ & 0.014 & 0.1096 \\
\hline $\mathbf{7}$ & 0.041 & 0.0813 \\
\hline $\mathbf{8}$ & 0.0667 & 0.0536 \\
\hline $\mathbf{9}$ & 0.083 & 0.0375 \\
\hline $\mathbf{1 0}$ & 0.0683 & 0.0518 \\
\hline $\mathbf{1 1}$ & 0.0528 & 0.0678 \\
\hline $\mathbf{1 2}$ & 0.0885 & 0.0445 \\
\hline $\mathbf{1 3}$ & 0.0929 & 0.0293 \\
\hline $\mathbf{1 4}$ & 0.0271 & 0.0998 \\
\hline $\mathbf{1 5}$ & 0.0895 & 0.0438 \\
\hline $\mathbf{1 6}$ & 0.1069 & 0.0222 \\
\hline $\mathbf{1 8}$ & 0.079 & 0.048 \\
\hline $\mathbf{1 8}$ & 0.0594 & 0.069 \\
\hline $\mathbf{2 0}$ & 0.0892 & 0.0435 \\
\hline
\end{tabular}


We measure the distance between each option from Euclidean method. We find the distance of options from positive and negative ideal options.

\section{Step 6: Calculating the proximity to the positive and negative ideal solution as well as the ranking of options}

Table 14: Proximity coefficient to positive and negative ideal solution and ranking nurses

\begin{tabular}{|l|l|}
\hline Result & Proximity coefficient \\
\hline $\mathbf{6}$ & 0.8866 \\
\hline $\mathbf{1 4}$ & 0.7866 \\
\hline $\mathbf{7}$ & 0.7859 \\
\hline $\mathbf{3}$ & 0.6647 \\
\hline $\mathbf{2}$ & 0.6188 \\
\hline $\mathbf{1 1}$ & 0.5873 \\
\hline $\mathbf{2 0}$ & 0.5624 \\
\hline $\mathbf{1}$ & 0.5567 \\
\hline $\mathbf{8}$ & 0.5483 \\
\hline $\mathbf{1 0}$ & 0.5375 \\
\hline $\mathbf{1 7}$ & 0.4455 \\
\hline $\mathbf{5}$ & 0.431 \\
\hline $\mathbf{1 2}$ & 0.3781 \\
\hline $\mathbf{1 5}$ & 0.3724 \\
\hline $\mathbf{9}$ & 0.3347 \\
\hline $\mathbf{1 3}$ & 0.3286 \\
\hline $\mathbf{1 6}$ & 0.328 \\
\hline
\end{tabular}

As shown in Table 14, nurse number 6 with a score of 0.8866 had the best performance compared to other nurses in terms of recipient services. Nurse number 16 also had the worst performance with score of 0.172 in comparison with other nurses in terms of recipient services.

\section{Discussion and conclusion}

Patients currently not only concern about the health received services, but also they pay attention to services that require high reliability, comfort and safety. Therefore, improving the quality of services is an essential process in the health care industry to meet the needs of patients. The benefits of improving quality include: increasing service performance, increasing customer satisfaction, and reducing the rate (amount) of complaint. OLAP has been introduced as a data warehouse for storing relevant data for the in-home care institute, elderly people, and nursing in an effective way, which allows managers of in-home care institute and nurses easily monitor and investigate the health of the elderly people. Subsequently, Topsis is used to evaluate the performance of nursing staff. The results are used to develop a suitable program for nursing staff to improve the quality of in-home care services. After conducting this research, the quality of in-home care services improved at in-hone care institute A in Rasht, and customers were more satisfied with the performance of nursing staff. Thus, it has been proven 
that IPAS is a practical way to improve the quality of services in home care agency. In the following, the results of the study are examined in two ways:

\section{A: Results to make a follow up plan}

The results of the IPAS can help the in-home care institution A to develop a proper follow-up plan for nurses. As Wilcoxon test showed, the elderly people satisfaction is promoted from inhome care institution $\mathrm{A}$ in all three dimensions: technical and vocational, education and trust. But the amount of dissatisfaction is still noticeable. However, elderly patients and their families are expected to receive high quality care at home. Some nurses believe they are constantly on a trip due to the large distance between residential homes of elderly patients. As a result, they may feel tired and therefore affect the work efficiency. Additionally, required trainings should be provided regularly for nursing staff to maintain their professionalism. For well performance nursing staff, rewards should be given to motivate nursing staff and enhance their loyalty.

\section{B: Advantages of IPAS proposed}

After IPAS implementation at the in-home care agency A for one month, it has been determined that (1) efficiency and accuracy in extracting valuable data and (2) the quality of in-home care services has been improved.

\section{1) Increasing efficiency and accuracy to extract valuable data}

After the implementation of IPAS proposed, managers of in-home care institute A can easily access and retrieve data from the OLAP data cube by collecting relevant data in the data warehouse. In addition, the regular updating of data in OLAP is important because it removes data errors by adding missing data and checking the accuracy of the data.

\section{2) Improving the quality of in-home care services}

By providing appropriate measures for nurses, the quality of in-home care services improved at in-home care institute A. The number of complaints in a week dropped significantly from 10 to 5 . Health care staff interviewed with 50 elderly patients who received in-home care services. The elderly patients were selected randomly. The results showed that the level of satisfaction with in-home care services was improved in three dimensions: technical and vocational, education and trust. This means that elderly patients are more satisfied with inhome care services by nurses than before the IPAS system is deployed. Also, according to the results, it can be said that nurses visit timely in-home elderly patients and are willing to take care of elderly patients more than before the IPAS system is deployed.

According to the results of the research, the following suggestions are presented: 1) In order to enhance the satisfaction of elderly people in the technical and vocational dimension, in-home care institution A should hold courses for nurses regularly or invite experienced nurses to increase their technical and vocational skill.

2) To improve the satisfaction of the elderly people in the education dimension, nurses should explain everything in simple language for the elderly people and, if necessary, explain the cause of the type of care from the medical point of view.

3) In order to promote the satisfaction of the elderly people in the dimension of trust, nurses should show their attention and understanding when listening to patients' problems and provide a sensation in the elderly people so that they can feel comfortable in asking questions from nurses.

4) For well performance nursing staff, rewards should be given to motivate nursing staff and enhance their loyalty. 


\section{References}

Ghasemi, Roohollah, Mohagher, Ali, Safari, Hossein and Akbari Jokar, Mohammad Reza. (2016). Applications of Technology of Internet of Things in Iran's Healthcare Sector: An Stimulus for Sustainable Development. Journal of Information Technology Management, Vol. 8, No. 1, Pages 176-155.

Yaqubī, Mahsa and Zoghi, Morteza. (2015). Model of health care system in emergency situations, based on the Internet of thongs. International Conference on Science and Technology, Tehran, Institute of Saramad, Karin Conference

Ahmad Alaiad And Lina Zhou. (2016). Patients' Adoption of WSN-Based Smart Home Healthcare Systems: An Integrated Model of Facilitators and Barriers. IEEE TRANSACTIONS ON PROFESSIONAL COMMUNICATION, VOL. 00, NO. 00,

Fang Hu, Dan Xie, Shaowu Shen. (2013). On the Application of the Internet of Things in the Field of Medical and Health Care. IEEE International Conference on Green Computing and Communications and IEEE Internet of Things and IEEE Cyber, Physical and Social Computing.

Khurana, Atul. (2015). OLAP Technology in Data Warehouses. International Journal of Advanced Research in Computer and Communication Engineering Vol. 4, Issue 8.

S. M. Riazul Islam, (Member, Ieee), Daehan Kwak2, Md. Humaun Kabir, Mahmud Hossain3, And Kyung-Sup Kwak1, (Member, Ieee). (2015). The Internet Of Things For Health Care: A Comprehensive Survey. Volume 3. 678-708.

Valerie Tang, K.L. Choy, Paul K.Y. Siu, H.Y. Lam, G.T.S. Ho, Stephen W.Y. Cheng. (2016). Proceedings of PICMET'16: Technology Management for Social innovation.

Zhibo Panga, Lirong Zhengb, Junzhe Tianb, Sharon Kao-Walterc, Elena Dubrovab and Qiang Chenb. (2014). Design of a terminal solution for integration of in-home health care devices and services towards the Internet-of-Things. Enterprise Information Systems, Vol. 9, No. 1, 86-116, http://dx.doi.org/10.1080/17517575.2013.776118. 